\title{
A TRADUÇÃO COMO FATO SOCIAL ${ }^{1}$
}

\author{
Sergey Tyulenev \\ Tradução de Diva Cardoso de Camargo 1 \\ Talita Serpa ${ }^{2}$ \\ 1 2 - Universidade Estadual Paulista Júlio de Mesquita Filho, São José do Rio \\ Preto, São Paulo, Brasil
}

\begin{abstract}
Resumo: O presente artigo propõe-se a uma releitura de obras clássicas de um dos fundadores da Sociologia Clássica, Émile Durkheim, em sua aplicabilidade para pesquisas na área de Tradução ${ }^{2}$. Considera, portanto, que, uma vez que a ação tradutória é compreendida como um fenômeno social dentro dos Estudos da Tradução, estes deveriam buscar por conceitos da Sociologia, a fim de não tentar "reinventar a roda". Sugere-se, então, que a Sociologia seja diferenciada da Psicologia de uma forma metodologicamente clara. Dentro desse campo, pesquisas individuais sobre traduções e tradutores, a não ser quando colocados em contexto social, não ajudam a compreender o processo como um fenômeno social. Metodologias para o estudo sociologicamente direcionado não poderiam, pois, edificar-se no senso comum, que, na maioria das vezes, acaba por dificultar ao invés de ajuda a ver a tradução como um fenômeno sociológico. Em outras palavras, em nossa investigação, a Tradução é trabalhada como um fato social e a necessidade de estudá-la como tal é fortemente enfatizada.
\end{abstract}

Palavras-chave: Sociologia e psicologia da tradução; Émile Durkheim; Tradução; Fato social

${ }^{1}$ Artigo publicado na revista Translation and Interpreting Sudies em 2014. A presente tradução foi autorizada para ser publicada em português pela Editora John Benjamins Publishing Company (<https://benjamins.com/ >) e pelo autor, Sergey Tyulenev, aos quais agradecemos imensamente. Referência bibliográfica completa do artigo original: Tyulenev, Sergey. Translation as a social fact. Translation and Interpreting Studies, v. 9, n. 2, p. 179-196, 2014.

${ }^{2}$ Faremos a distinção entre tradução (produto) e Tradução (área do saber, Ciência). 


\title{
THE TRANSLATION AS A SOCIAL FACT
}

\begin{abstract}
The article proposes a re-reading of classical works of one of the founding fathers of sociology, Emile Durkheim, in their applicability to translation research. It is argued that, since translation is a social phenomenon, TS, in theorizing translation, should learn from sociology in order not to reinvent the wheel. It is suggested that the sociology of translation should be distinguished from the psychology of translation in a methodologically clear way. Within the sociology of translation, studies of individual translations and translators, unless put into social context, do not help understanding translation as a social phenomenon. Methodology of the sociologically informed study of translation should not rely on common sense, which more often than not turns out to hamper, rather than help to see translation as a sociological phenomenon. In other words, translation is shown as a social fact and the need to study it as such is strongly emphasized.
\end{abstract}

Keywords: Sociology and psychology of translation; Emile Durkheim; Translation; Social fact

\section{Do sincretismo à síntese por meio da análise}

Os Estudos de Tradução (doravante ETs) encontram-se em um ponto de bifurcação. Dessa forma, se sua história pode ser descrita como uma série de sinuosidades (Snell-Hornby (A), (B)), então, há claros indícios de que a análise social em áreas da Tradução com a ajuda de Teorias Sociológicas também deve ser entendida como um desses meandros (Wolf).

Tais fatores vêm sendo discutidos atualmente nos ETs, ou seja, considera-se se a Tradução deve abordar o tradutor ou a prática tradutória; se o foco principal das pesquisas concentra-se na ação ou na estrutura do processo. Assim, a mais profunda implicação desse tipo de discussão, que não parece ter sido muito apreciada, é aquela que considera se o conteúdo teórico dos ETs está hospedado no domínio da Psicologia, a princípio e, em seguida, engloba a Sociologia; ou se incorpora imediatamente esta última Ciência de maneira plena em suas proposições. 
Além disso, propõe-se outro questionamento, a saber: A qual dos dois âmbitos, Psicologia ou Sociologia, deve ser dada a preeminência? Nem todos perceberam o dilema de se combinar as duas áreas, mas a problemática está ali e precisa ser resolvida de alguma forma, afinal, o híbrido da Psicossociologia, criada a partir da junção de ambos, pode não perdurar.

Parece haver uma preferência por priorizar os tradutores em relação aos textos traduzidos (TTs), afastando, assim, o dilema "tradutores vs. tradução" da polêmica dicotomia "Sociologia vs. Psicologia" 3 . Contudo, tal fator não contradiz nossos propósitos sociológicos, pelo contrário, enfatiza a hipótese de que nenhum estudo sobre tradutores é possível sem a compreensão do que constitui a Tradução como um fenômeno social. Tal entendimento pode ser científico ou apenas pautar-se no senso comum, mas, por trás de qualquer pesquisa em ETs, deve estar latente o entendimento dos fatores que tornam a Tradução uma prática social.

De fato, como pode o tradutor ser assim chamado sem uma visão explícita ou implícita, científica ou, pelo menos, comumente compartilhada, clara ou difusa, do tipo de ação que ele executa, e por meio da qual pode ser considerado tradutor? Nesse sentido, nos ETs, se, hoje, alguém, procurando revitalizar a definição de Tradução, inquerisse, de uma forma mais profunda, como poderia conduzir sua pesquisa, encontraria uma ideia (talvez ainda nebulosa e tangente à superfície) do que é de fato Tradução e de como iniciar uma investigação na área?

Com efeito, a Tradução, entendida como atuação (ação ${ }^{4}$, é vis-

3 Veja mais das dicotomias "Sociologia/Psicologia" e "coletivo/ individual" de Durkheim em Lukes (1971, p. 193-197).

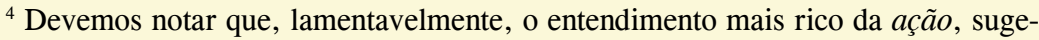
rido pelos participantes do simpósio “Translators' Agency” na University of Tampere, em 2008, foi vítima do mesmo senso comum que compara a ação tradutória a uma ação humana, a qual os editores do simpósio argumentaram com a subsídios em Buzelin. Em seu esforço coletivo, definiram a ação como "a disposição e a capacidade para agir", onde a vontade é "ligada à consciência, à refletividade e à intencionalidade, e não sem alguma fundamentação moral ou ética" e "é bastan-

Cad. Trad., Florianópolis, v. 39, no 2 , p. 339-378, mai-ago, 2019. 
ta como apenas um outro lado de uma estrutura. Não importa o quanto tentemos (enquanto desvendamos a interação entre estrutura e ação de traduzir) desmascarar este arcabouço primário, acabamos sempre por esbarrar em todos os caminhos silogísticos e passagens de um sofisticado labirinto argumentativo sobre a ação. De fato, entende-se que ela (a ação) é estruturada e ainda mais estruturante, porque, como os peixes não podem viver sem água, a ação não pode existir sem a estrutura.

Anthony Giddens toca o dedo na ferida quando afirma que “(...) o que Durkheim frequentemente chama de o 'culto do indivíduo' é algo criado pela sociedade: isto é, há uma inadequação do utilitarismo como Teoria Social, porque o que se toma como premissa é, na verdade, o resultado de um processo de longo prazo de desenvolvimento social" ${ }^{5}$ (211).

Ou seja, a realidade é muito mais complexa do que qualquer binário, mas, quando as prioridades de pesquisas acadêmicas vêm à tona, a questão não é encontrar uma teoria que possa descrever toda a realidade em toda a sua complexidade, porque isto seria impossível. Seja qual for a abordagem, inevitavelmente, reduzir-se-á a realidade: uma hipótese binária deixa de trabalhar o continuum; uma suposição não-binária não explora com clareza as oposições envolvidas. Por conseguinte, assim como na Teologia, a fim de não ser condenado como um herege, um pesquisador começa sempre com o Credo in Unum..., e posteriormente analisa as hipóstases da Trindade ou vice-versa; em estudos sociologicamente direcionados, outras formas de investigação devem ser reconhecidas.

O problema da associação dessas Ciências é que não há nelas uma metodologia que seja diferente a depender de onde iniciemos a análise, ou seja, ora pelos polos (extremos); e/ou ora pelo con-

te individualista e psicológica por natureza" (Kinnunen, Koskinen, 2010, p. 6). Como atores não-humanos como amêijoas ou computadores (cf. Callon, 1986) têm tal vontade? Além disso, a Psicologia e a Sociologia não se distinguem na proposta de definição.

${ }_{5}$ As citações foram traduzidas a partir das versões em inglês utilizadas por Tyulenev no corpo de seu artigo.

Cad. Trad., Florianópolis, v. 39, no 2, p. 339-378, mai-ago, 2019. 
tinuum (entre os dois pontos em estudo). O desafio, portanto, é encontrar um ângulo [sincretismo] que permita ao analista buscar um caminho claro de observação do fenômeno em questão, porque, caso contrário, não haverá qualquer garantia nem prova convincente de que os resultados da pesquisa serão válidos.

O sincretismo das teorizações, contudo, não deve ser confundido com síntese. O primeiro implica um amálgama de fenômenos mistos, em que nenhum elemento se destaca; a segunda, por sua vez, coloca os fatores em conjunto após terem sido estudados separadamente, chegando à conclusão de que, para entender o todo, o estudo das partes deve ser realizado concomitantemente. $\mathrm{O}$ sincretismo é o antes; a síntese é o depois.

Sem dúvida, ambos posicionamentos são necessários para a condução de pesquisas científicas, tanto do ponto de vista do/s tradutor/es (indivíduos) socializado/s, quanto no âmbito da Tradução como fenômeno social. No entanto, não se trata de um propósito fácil de ser mantido, uma vez que nem as boas intenções nem o uso de terminologias sociais em sociobiografias ou a associação de renomados pesquisadores aos temas de um estudo os tornam, de fato, trabalhos sociologicamente fundamentados; principalmente, se o restante do estudo continuar sendo um emaranhado de "velhas histórias" com conjecturas como aquelas em que se considera o que o tradutor "sentiu", e mesmo o que "sonhou" (como se confessasse algo ao pesquisador).

Tais tentativas permanecem bastante superficiais, apesar de suas professas ambições sociológicas, porque o que realmente se tenta obter, até o momento, é uma sociopsicologia, a qual, contudo, requer, primeiramente, uma compreensão clara da natureza de ambas as formas de investigação: Psico e Sociológica. Caso contrário, o trabalho permanecerá no nível de ambição teórica e bem longe da aplicabilidade.

As conclusões de tais estudos tendem a apresentar um nível mais elevado que as pautadas no senso comum, tendo pouca força explicativa e pouca aplicabilidade nas análise de biografias de tradutores. Em outras palavras, a Psicologia e a Sociologia, como 
água e óleo, permanecem separadas e não há resultados sociopsicológicos concretos.

No presente artigo, acredita-se que, como a Tradução é, intrinsecamente, um fenômeno social, seus aspectos sociais devem ser levados em conta, mesmo se um estudo sobre a prática de um indivíduo-tradutor estiver em pauta. Por tal razão, é imperativo ser claro sobre em que sentido e em que medida a Tradução é um fenômeno social; isso significa que não se pode confiar em na compreensão comum de Tradução como sendo influenciada por/ influenciadora da sociedade, e, portanto, (simples assim!) um fenômeno social.

Tal perspectiva deve ser mais avançada do que entender a Tradução apenas como um fator de equivalência linguística, mas também ir além da simples ideia de que um fenômeno social se trata de algo que, de alguma forma, está relacionado à sociedade. Essa, no entanto, ainda é a lógica de quase todas as pesquisas com ideal sociológico nos ETs.

O pesquisador, ao considerar essa primeira noção como dada, passa para um segundo estágio, ou seja, responder: Como a Tradução se relaciona com a sociedade? Alguns autores explicam tais fenômenos de acordo com Teorias Sociológicas, ao passo que outros optam por conceitos de outras Ciências Sociais. Contudo, o elemento fundamental escapa aos analistas da Tradução desde que começaram a falar sobre este fenômeno em associação com a Sociologia, ou seja, sem os saberes fundamentais da área, os estudiosos de Tradução não compreendem profundamente as proposições de Bourdieu, Lahire, Luhmann, Latour, Callon, Giddens, Renn, etc.; como resultado, nem todos nos ETs se convencem de que a Tradução é social uma vez que precisamos de mais teorizações para comprovar tal fato, e aqueles que estão convencidos (raras exceções) tendem a desenvolver pesquisas pautadas em ideias simplistas, amadorismos e de bases psicológico-cum-sociológicas.

Os estudos sincréticos não são o foco de investigação em nossa análise, visto que a reflexão se concentra em uma perspectiva que perpasse a fase do "Psicológico vs. Sociológico". Então, ao 
se reconhecer a diferença entre ambos, e quanto a Psicologia e a Sociologia oferecem aos ETs, é possível avançar para a realização de pesquisas mais sintéticas e complexas. Os ETs contemporâneos vão além deste estágio sincrético de esforços teóricos psicossociais.

Assim sendo, algumas considerações terminológicas são necessárias para dar prosseguimento aos estudos. A Tradução tem sido compreendida com um fato social descrito pelo Ativismo Social (Zlateva; Way). Não há nada de errado em denominar a Tradução como ação social dentro deste conceito, no entanto, ao considerar os envolvimentos da Tradução em processos sociais, algumas abordagens sociológicas e suas respectivas terminologias serão o fio condutor do presente artigo.

A Sociologia tem explorado a natureza do social por mais de um século e tem desenvolvido uma refinada malha de instrumentos analíticos dos quais os ETs podem fazer uso. Em Sociologia, o termo ação social é amplamente explorado, mas, aqui, o ponto a ser observado não é o termo em si, não havendo motivos para que se crie um conflito terminológico - é o conceito por trás de tudo que está em pauta.

Portanto, o propósito deste trabalho não é tão ambicioso quanto analisar a aplicabilidade e o potencial da Sociologia para os ETs em geral. O objetivo é mais humilde: Apresentar aos estudiosos da Tradução alguns importantes escritos de um dos pais da Sociologia Moderna, Émile Durkheim (1858-1917). Seus trabalhos são reconhecidos como clássicos atemporais e são de especial relevância para os ETs na bifurcação acima referida, porque dedicaram-se aos mesmos assuntos - o que exatamente faz do social social. Então, vamos voltar ao ponto de partida.

Não é preciso envergonhar-se de ter que aprender as base da Sociologia de Durkheim. Ao fazer isso, os ETs associam-se a muitas outras disciplinas, incluindo a Sociologia por si mesma (Thompson 13). Clássicos, como Durkheim, "[...] definem um precedente histórico que permitiu o desenvolvimento de muitas outras análises posteriores" (Fish 4). Uma vez que os ETs estão apenas iniciando a exploração das propriedades sociais de seu objeto, tais estudos so- 
ciológicos como os pressupostos durkheimianos certamente devem ser bem-vindos como uma base para o avanço científico da área.

Na virada do século XIX (1890-1917), Durkheim, conforme Kenneth Thompson, "[...] contribuiu para a fundação da Sociologia Moderna mais do que qualquer outro pesquisador" (Durkheim, 1). Formulou noções fundamentais de Sociologia, como fato social; também delineou um método sociológico e produziu uma série de estudos de caso em que demonstrou como aplicar seus procedimentos, entre eles podemos mencionar os livros As Regras do Método Sociológico (1895) e $O$ suicídio (1897), os quais comporão as bases desta discussão. Em 1898, Durkheim fundou a revista L'Année sociologique, onde publicou seus próprios escritos e de seus aprendizes com o objetivo de promover avanços da Sociologia como disciplina acadêmica.

As publicações de Durkheim foram, nas palavras de Thompson, “[...] calculadas para chocar", "[...] sua abordagem [sendo] deliberadamente contraintuitiva e oposta aos pressupostos préconcebidos sobre a natureza e as causas dos fenômenos sociais" (Durkheim, 2). Insistiu que a Sociologia tinha que ter o seu próprio objeto irredutível, sem qualquer interferência de ciências adjacentes, entre elas a visão da Psicologia e, particularmente, da Filosofia Utilitarista, da sociedade como um "conjunto de indivíduos agregados atuando racionalmente em termos de utilidade e auto-interesse" (Durkheim, 2).

Ao longo dos anos, depois da atuação de Durkheim, a evolução de como a ação social é descrita foi intensa, de tal forma que, aqui, incorporam-se alguns desses desenvolvimentos à argumentação; considerando-os aplicados à Tradução de uma maneira completa, para que esta se torne objeto de estudos independentes.

A teoria de Durkheim é tomada a partir da convicção de que suas hipóteses fundamentaram o conceito de fato social e de que tal perspectiva garante sua releitura como base para o presente estudo.

$\mathrm{O}$ foco em Durkheim pode também ser justificado como um primeiro passo, pois a aplicação de suas teorias fundamentais nunca foi levada em conta nos ETs. Assim sendo, os termos da Psicologia 
e da Sociologia são utilizados, em um sentido durkheimiano, de modo que a diferença mais importante entre eles é que a primeira procura explicar as ações individuais, enquanto que a última - as coletivas.

Durkheim definiu Sociologia em As Regras do Método Sociológico como "[...] a ciência das instituições, de sua gênese e de seu funcionamento" (2004, 3). Tal compreensão da sociedade, como veremos, apresenta um grande valor para os Estudos da Tradução.

\section{Sociologia vs. Psicologia}

A Tradução é um fenômeno social e, portanto, deve ser estudada sociologicamente. Estudos Sociológicos da Tradução nos levam a aplicar a este fenômeno todas as propriedades de ação social e, em primeiro lugar, separá-la dos fatores de base psicológica.

Durkheim insistia que, assim como o domínio biológico é separado do psicológico, também o psicológico deveria ser separado do social. Isso conduz a uma importante exigência metodológica: "[...] recusamo-nos a explicar o mais complexo em termos do mais simples" (Durkheim, 54). Isso significa que não se devem confundir as ações individuais com as coletivas, mas isto não significa dizer que ações individuais não possam ser estudadas. A questão é como explicar que o que se observa em termos de razões psicológicas simples tem motivações sociológicas bem mais complexas?

Em uma de suas obras clássicas, Émile Durkheim mostrou como, mesmo parecendo ser puramente individuais (psicológicas), determinadas ações podem ser, fundamentalmente, ações sociais, trazendo o suicídio como exemplo. Pode o suicídio ser de interesse para o sociólogo?

O suicídio parece ser "[...] o ato de um indivíduo que diz apenas respeito ao indivíduo" de acordo "[...] inteiramente com fatores pessoais," por isso, talvez, seria de interesse apenas dos psicólogos, uma vez que é "[...] normalmente explicado pelo temperamento de [um indivíduo], bem como por seu caráter, antecedentes e aconte- 
cimentos de sua história privada" (Durkheim (B) 21). Entretanto, Durkheim não concordava com este ponto de vista simplista sobre o suicídio e demonstrou, estatisticamente, que, em diferentes períodos de sua história, as diferentes sociedades têm distintas disposições para o suicídio, ou seja, há relação entre o número de suicídios e o contingente populacional total. A expressão estatística dessas disposições é a taxa de suicídio-mortalidade da sociedade em questão (Durkheim (B) 24). São tais disposições que vêm "[...] de dentro da órbita da Sociologia” (Durkheim (B) 28). O foco da atenção de Durkheim é claramente afastado dos motivos que condicionam suicídios em particular; ele investiga apenas contextos maiores, mais condições gerais que determinam a taxa social de suicídio:

É claro que as duas questões são bastante distintas, qualquer que seja a relação que possa existir entre elas. No tocante às condições individuais, há, certamente, muitas que não são suficientemente generalizantes para afetar a relação entre o número total de voluntários à morte e a população. Essas [condições], talvez, conduzam este ou aquele indivíduo isolado a matar a si mesmo, independentemente de a sociedade como um todo ter uma tendência mais forte ou mais fraca para o suicídio. Assim, não se referem a um estado particular de organização social, de modo que não têm quaisquer repercussões sociais. Como resultado, dizem respeito ao psicológico, não ao sociológico. O que a Sociologia investiga são as causas pelas quais se pode agir sobre os indivíduos não apenas isoladamente, mas em grupo. Consequentemente, entre os fatores de risco de suicídio, os únicos que nos preocupam são os que têm um efeito sobre o conjunto da sociedade. A taxa de suicídio é o produto destes fatores, e é, por isso, que devemos nos preocupar com eles. (Durkheim (B) 28-29)

Os questionamentos de Durkheim sobre a natureza social do suicídio, em primeiro lugar, mostram que causas extrassociais do 
suicídio são bastante restritas (nem as chamadas monomanias suicidas nem qualquer estado de psicopatia pode ser considerado como tendo "[...] regular e incontestável relação com o suicídio" (cf. Durkheim (B) 39)); em segundo lugar, determinam a natureza das causas sociais e o mecanismo de seus efeitos sobre diferentes grupos e sociedades; e, em terceiro lugar, definem o elemento social do suicídio e a sua relação com outros fatos sociais.

Vemos que como sociólogo, Durkheim, acima de tudo, separa a Psicologia da Sociologia do suicídio. A clareza desta estância metodológica permite-lhe encontrar e descrever o que, portanto, havia sido mal compreendido - que o suicídio, ao contrário da crença comum, é constituído, primariamente, como uma ação de cunho social. Como Richard Sennett resume, em "O Suicídio, [Durkheim] nos pede para concentrar em assuntos tais como o tamanho da família, a estrutura do núcleo familiar e a mobilidade ascendente [...]; a obra adverte-nos contra a procura de respostas com base na Psicologia" (Durkheim (B) 23).

Sabemos que a Tradução é bastante diferente do suicídio em muitos aspectos. Por exemplo, pode argumentar-se que a exposição a influências sociais na Tradução é mais extensa e duradoura que uma decisão impulsiva de tirar a própria vida voluntariamente. No entanto, como Durkheim mostrou, o suicídio, embora impulsivo, é resultado de um contínuo de forças sociais. É esta parte - as influências sociais - que está no centro de seus propósitos sociológicos; são as interferências da sociedade que fazem o suicídio e a Tradução comparáveis. Portanto, o pesquisador em Tradução pode, definitivamente, entender o estudo sobre o suicídio realizado por Durkheim como um exemplo de aplicação do método sociológico.

Isto é especialmente importante porque é difícil - em tal perspectiva comum de ações individuais, como o suicídio e a Tradução - observar o social através do individual. Para citar Richard Sennett mais uma vez:

Os fatos sobre os quais as pessoas são imediatamente conscientes são enganosos. Abaixo desta camada, as pessoas 
sentem e pensam por outras vias: minha família é pequena ou ausente (egoísmo); eu não estou lutando ao lado de meus companheiros (altruísmo); o meu sucesso não me preenche (anomia). [...] Muitos poucos suicidas são susceptíveis em deixar uma nota que explique 'estou apontando uma pistola para minha cabeça por causa de anomia'. (Durkheim (B) 22-23)

Embora a anomia seja um problema, o que há de fato é uma dinâmica entre o externo e o interno, entre o psicológico e o sociológico, em cada caso de suicídio ou de Tradução. "Em termos contemporâneos, este tipo de assunto surge nos debates sobre, por exemplo, a maneira em que o pessoal é também político. [...] A sociedade é sempre de dentro e de fora - e Durkheim foi capaz de reconhecer isso" (Craib 32).

Mas antes de tudo, sem dúvida, é preciso estabelecer o âmbito sociológico do problema, ou seja, "[...] fatos sociais [...] são externos e internos (i.e. internalizados por) qualquer indivíduo; e eles são apenas externos para todos os indivíduos, na medida em que têm sido culturalmente transmitidos desde o passado" (Lukes 190).

Lamentavelmente, os atuais ETs não possuem uma clara visão da Tradução como um objeto de pesquisas sociologicamente direcionadas. Embora o entendimento de que a Tradução é um fenômeno socialmente determinado tenha ganhado terreno, grande número de pesquisas são, ainda, um misto de biografias, retratos de tradutores, histórias emocionantes de sucessos e fracassos de obras traduzidas, levando em contas as influências de tradutores/traduções sobre a sociedade, a cultura e as línguas nacional(istas) dos discursos, bem como a mediação durante a guerra ou a paz, etc.

Para evitar qualquer mal-entendido, esta crítica não é para ser entendida como uma negação de investigações socialmente relevantes, mas sim para apontar a falta de clareza metodológica quando fatos psicológicos e sociológicos não se distinguem e são apresentados, em grande parte, indiscriminadamente, em um trabalho de investigação com pouca justificação de colocá-los juntos. 
Mutatis mutandis, esse é exatamente o porquê de Durkheim criticar os primeiros sociólogos:

[...] tudo o que sabemos sobre a forma como as ideias individuais se combinam pode ser reduzido às poucas, generalizantes e vagas proposições que são comumente chamadas de leis de associação de ideias. Assim, as leis da reflexão coletiva acabam sendo ainda menos conhecidas. A Psicologia Social, cuja tarefa deve ser a de determinar essas leis, não é mais do que uma palavra que denota todos os tipos de variadas e imprecisas generalidades sem objeto definido. (56)

A Sociologia vê as ações humanas como "elementos de maior figuração" (Bauman 7-8). Isso significa que as ações humanas são vistas como realizadas por atores mutuamente dependentes. Esta dependência é entendida como a probabilidade de cada ação social, seu desempenho e/ou sua chance de sucesso, sendo determinados diretamente ou indiretamente por meio das relações entre os atores.

A Sociologia considera as ações humanas em "redes de dependência mútua" (Bauman 8). Atores individuais interessam a esta ciência como unidades em redes de interdependências. Este ponto de vista, que é fundamental aos sociólogos, por vezes é esquecido quando, por exemplo, em sua tentativa de aplicar o conceito de habitus de Pierre Bourdieu, alguns estudiosos em ETs usam a noção de habitus como intercambiável com a ideia de biografia ou de história de vida. Por exemplo, em Torikai (2009), no capítulo 3 de seu trabalho, denominado "Habitus", inicia da seguinte maneira: "[n]este capítulo, as histórias de vida de cinco intérpretes pioneiros em seus primeiros anos serão introduzidas" (49).

No capítulo seguinte, associa outro conceito bourdieusiano, o de campo, com histórias de vida: "[n]este capítulo, as histórias de vida dos cinco intérpretes serão analisadas com foco no início de suas carreiras, para verificar como eles contribuíram para o "campo' de interpretação" (85). 
O conceito de habitus de Bourdieu, no entanto, é fundamentalmente sociológico (visando ver "o social no individual, o geral no particular" (Bauman 10)) e não pode ser reduzido à biografia ou à história de vida, porque o seu foco é a interdependência dos atores, sendo influenciada pela sociedade e tendo suas repercussões sobre a mesma, nada menos do que uma via de mão dupla em direção ao ator e a partir dele, e, especialmente, a natureza complexa e a dinâmica profunda destas transações.

Nos ETs atuais, descreve-se o habitus como sendo bastante popular e visto como uma solução equilibrada de oposições binárias indesejadas entre "indivíduo vs. sociedade" e "ação vs. estrutura". Assim retratar o habitus de um tradutor, resumindo-se a descrever como ele aprendeu a amar os livros, cresceu e foi para a escola bilíngue/bicultural (multilíngues/multiculturais) e, em seguida, como adulto, traduziu apesar de/de acordo com tendências socialmente determinadas, não é, de fato, apresentar o habitus, mas sim a biografia do tradutor.

Assim, tais descrições pouco auxiliam os ETs, em seus objetivos sociológicos, a se consolidar como disciplina acadêmica com a capacidade de ir para além dos indivíduos e ser capaz de generalizar os fenômenos estudados. Não se trata de argumentar contra os estudos de caso nos ETs, o que se defende, aqui, é que o pesquisador deve olhar mais longe e perguntar a si mesmo, após a realização de um estudo de caso: O que faz o estudo de um indivíduo em particular mostrar-nos algo geral, que é geral porque é coletivo?

Os fenômenos sociais não podem ser explicados por fatores psicológicos, sendo assim, "[...] para compreender o modo como a sociedade concebe a si e ao mundo que a rodeia, é a natureza da sociedade e não a dos indivíduos que deve ser considerada" e "[...] mesmo que a psique individual não tenha mais segredos para nós, não pode fornecer a solução para qualquer um dos problemas [sociais], uma vez que que eles se relacionam com ordens de fatos que está desconhece" (Durkheim (C) 40-41). Se assim fosse, o que uma compreensão mais profunda de uma história de vida de um tradutor contar-nos-ia sobre o fenômeno da Tradução? 
Para evitar qualquer mal-entendido, pesquisas psicosociológicas não foram refutadas por Durkheim, ao contrário:

\begin{abstract}
Mas, uma vez que essa diferença de natureza [entre o psicológico e os fatos sociais] é reconhecida, pode-se perguntar se representações individuais e representações coletivas, não obstante, se assemelham umas às outras, uma vez que ambas são igualmente representações; e que, como consequência desta similaridade, certas leis abstratas podem não ser comuns aos dois domínios. Mitos, lendas populares, concepções religiosas de toda espécie, moral, crenças, etc., expressam uma realidade diferente da realidade individual. Mas pode ser que a maneira com que os dois se atraem ou repelem, aderem, unem ou separam seja independente do seu conteúdo e relacionem-se somente com a qualidade geral de serem representações. Enquanto forem formulados de modo diferente, irão comportar-se bem em suas interrelações, assim como sentimentos, imagens ou ideias do indivíduo. Ninguém, por exemplo, poderia acredita que a proximidade e a semelhança, os contrastes e a lógica de oposições atuam da mesma forma, não importando o que as coisas estão representando? Assim, chega-se à possibilidade de uma Psicologia inteiramente formal que pode compor um terreno comum com a Sociologia. Talvez esta seja a razão de certas mentes sentirem escrúpulos ao distinguir tão acentuadamente as duas ciências. (Durkheim (C) 41)
\end{abstract}

Dessa forma, como aponta Susan Jones (132-133), as críticas a Durkheim, supostamente, negligenciam questões maiores e são baseadas na incompreensão ou na falta de conhecimento sobre suas proposições.

Determinadas causas levam um fato social a ser encontrado entre fatos sociais antecedentes e "não entre os estados da consciência individual" (Durkheim, 76), porque a consciência coletiva é distinta da consciência individual, que "só pode ser realizada por meio de pessoas" (apud Lukes 184). 
Durkheim explica a ruptura entre a Psicologia e a Sociologia referindo-se à quebra entre as teorias da Biologia, Física e Química. A diferença entre fatos sociais e psicológicos não é apenas de qualidade, mas de substrato, de ambientes e de condições de existência. Fatos sociais e psicológicos têm naturezas completamente diferentes, porque são diferentes representações:

\begin{abstract}
A mentalidade dos grupos não é a mentalidade dos indivíduos; ela tem suas próprias leis. As duas ciências [Psicologia e a Sociologia] são, portanto, claramente distintas como duas ciências podem ser; qualquer que seja o relacionamento não pode ser de outra forma entre elas. (Durkheim 55)
\end{abstract}

Se os ETs tivessem uma clara compreensão disto, não haveria dificuldades com as teorizações de Luhmann sobre a sociedade sendo composta por ações sociais e não por seres humanos. Podem haver divergências; e diferentes argumentações poderiam ser sugeridas, mas a perspectiva de Luhmann não seria, como é atualmente, uma pedra no sapato para alguns dos pesquisadores sobre Tradução.

Não seria ingênuo tentar explicar a Tradução como um fenômeno social, mostrando tradutores individuais/tradutores e suas experiências, ou seja, "os estados de consciência individual", mas, em vez disso, haveria mais investigações sobre as "representações coletivas", indo muito além de simples generalizações sobre tais representações como formas de expressão de como "o grupo se pensa nas suas relações com os objetos que o afetam" (Durkheim 55). Grupos, objeto de estudo sociológico, e indivíduos são constituídos de formas diferentes e afetados por "coisas" diferentes. Assim, "[...] representações que exprimem nem os mesmos sujeitos nem os mesmos objetos não dependem das mesmas causas. Para compreender a maneira como a sociedade concebe a si e ao mundo que a rodeia, precisamos considerar a natureza da sociedade, e não a natureza dos indivíduos" (Durkheim 55). 
A visão da Sociologia sobre a Tradução (como ação social) implica o desenho de imagens maiores, indo além de qualquer ato tradutório/ interpretativo individual em particular. Devemos nos esforçar para ver mais padrões gerais - socialmente relevantes, além de incluir, em nossa concepção de Tradução, uma soma total de todo passado, presente e futuro de eventos tradutórios possíveis, com o objetivo de estudar o ato tradutório como um determinado fenômeno social, diferente de qualquer outro, uma ocorrência sui generis - manifesta em maneiras particulares de agir.

Se, pelo contrário, os textos traduzidos são vistos como manifestações intrinsecamente individuais de vontades particulares, resistindo a maiores generalizações, em seguida, cada ato tradutório tornar-se objeto primário da Psicologia. Neste último caso, no entanto, não fica muito claro como podemos identificar diferentes atos psicológicos como pertencentes à atividade de Tradução.

Se tal questão fundamental é impossível de se resolver, o que podemos dizer sobre as estratégias (a partir do moderno ponto de vista) de processamento de texto e linguagem, bem como sobre as emergentes culturas nacionais da Antiguidade ou da Idade Média (Mcelduff, Sciarrino)? Em que base podem ser comparadas (se é que podem) com os modernos fenômenos sociais a que nos referimos como traduções (Swansea)? Ou sobre o que podem sustentar-se diferentes tipos de mediação de textos entre línguas e culturas justapostas (Bandia and Bastin 2010; Ricci and van Der Putten, 2011)?

Isto não pode ser tão supervalorizado que a declaração e a teorização da Tradução como um ato psicológico, inevitavelmente, nos levem a um impasse lógico. De fato, se os atos tradutórios são psicológicos, como, então, considerar a conexão entre eles? O princípio do que é Tradução não mais deve ser denominado de tal maneira, visto que a epistemologia parece ser pautada somente no senso comum, e essa base (como a pesquisa pós-colonial torna muito claro) é instável e não pode reclamar o princípio de ser científica.

Neste ponto, não importam as convicções, é necessário reconhecer o pano de fundo social que determina que todas as traduções são Tradução, todos os fenômenos tradutórios individuais são fe- 
nômenos tradutórios sistêmicos, todos os fenômenos relacionados a estudos psicológicos sobre tradutor/intérprete (s) devem, finalmente, ser sociologicamente contabilizados; caso contrário, a investigação deve ser limitada ao estudo do papel de fatores mentais e emocionais para as atividades tradutórias. Dessa forma, sempre que for possível ir além dos fenômenos psicológicos, inevitavelmente acaba-se no domínio sociológico.

Para enfatizar, quando a definição de Tradução é fornecida por praticantes e por consumidores de "tradução-como-um-produto", o que implica em deixar que Tradução seja tudo o que todos entendem por traduzir, o conceito torna-se novamente suspeito do ponto de vista epistemológico. E se, em algum lugar, em algum momento da história, o que se chama de Tradução não foi assim referido? Deve-se incluir este fenômeno na investigação ou abandoná-lo? E se o que se chama de Tradução fosse outrora conhecido por "combinatória" ou "chamariz" e mesmo por outros nomes não menos surpreendentes (Cheung); ou se a Tradução fosse comparada a uma corrida de carros na Califórnia (Robinson 261)?

Estas perguntas podem ser feitas de outra maneira: E se algo for chamado de Tradução, como é o caso de alguns tipos de discurso, mas tiver um significado bem diferente do que o usual, como, por exemplo, na teoria da "rede de autores" (Callon)? Recusa-se a considerar a Tradução como tal? Mas, por que e com que bases pode-se incluir ou excluir algumas atividades sociais na/da conceituação de Tradução?

Volens-nolens a questão fundamental volta a aparecer: o que é Tradução? E mesmo o conceito de jogos [de linguagem] de Wittgenstein pouco auxilia nos ETs, afinal, quais deles podem ser associados à atividade tradutória e a quais é negada tal honra? Há ainda outra questão: Que língua(s) deve ser selecionadas para a caminhada incessante pelos continentes em busca de fenômenos de Tradução?

Generalizações sociológicas assombram, afinal, mesmo se fosse apenas um tradutor em foco, seu trabalho não poderia ser considerado como uma expressão de um contexto social complexo. Os tradutores não podem ser estudados sem a compreensão da atividade 
social que os constitui como tradutores. A Tradução é sempre um ato socializado (Toury 53-55).

Tradução (ões) (plural) não podem ser estudadas somente como manifestações da Tradução (singular). A Tradução (singular) é uma somativa de atividades sociais, a qual é composta de todas as ações tradutórias que interagem e formam vetores de preferências de determinação de normas, padrões, tradições, inclinações, etc., o que são claros vestígios de outra forma indescritível de Tradução.

Normas, e os demais elementos sociais, são um sinal da presença de fatores incógnitos da Tradução. Ao longo do tempo, essas normativas podem ser muito distintas, mas, por meio de um conceito de tradução ${ }_{1}$ (em um tempo e espaço) e outro conceito de tradução ${ }_{2}$ (em outros tempo e espaço) ... e tradução ; nós, inevitavelmente, chega-se à proposta de tradução ${ }_{0}$, porque, se não houver tradução ${ }_{0}$, como pode ser que tradução ${ }_{1},{ }_{2} \cdots_{n}$ sejam entendidas como traduções e como podem múltiplas traduções definirem um conceito de Tradução único (Halverson)? Digno de nota é que quando Gideon Toury relativizou a Tradução em seus estudos, sugeriu três postulados ${ }^{6}$ para sua definição (Toury (B) 31).

A resistência a uma definição fixa de Tradução (visto que tal definição é temida por alguns estudiosos dos ETs por impor um caráter unificador a uma variedade de traduções realizadas, no espírito de um pós-colonialismo mal aplicado em diferentes partes do mundo) parece estar associada a razões político-ideológicas que pouco têm a ver com Ciência.

A firme convicção é a de que não se trata apenas de uma questão do que denominamos tradução ${ }_{1}, 2 \ldots$, mas sim de algo mais intrínseco, acerca de tudo que as torna comparáveis. De maneira simplificada, a Tradução pode ser expressa formulaicamente como $A \leftrightarrow M \leftrightarrow B$, em que A e B são partes interagentes e M é o mediador

${ }^{6}$ A relativização de Toury da definição de Tradução, que é crucial para tornar os ETs mais inclusivos para a pesquisa empírica, mais crucial para os Estudos da Tradução pós-coloniais, é normalmente limitada e o balanceamento de parte dele, com os três postulados (a fonte, a transferência e a relação) são, muitas vezes, deixados de fora, qualquer que seja a razão.

Cad. Trad., Florianópolis, v. 39, no 2 , p. 339-378, mai-ago, 2019. 
entre elas, seja qual forem as formas que estas estruturas possam assumir (Tyulenev 35-44, 57-64).

Os termos somativo ou soma total não sugerem simples adição de todas as traduções. Estas relações excedem a pura matemática da equação $(1+1=2)$; em vez disso, é preciso de lidar com relações sociais sistêmicas emergentes. Os escopos diferentes podem focar em escolas de pensamento, práticas, locais e períodos históricos distintos. Qualquer que seja o foco, uma coisa deve ser clara: nenhuma tradução individual é redutível a si mesma, mas deve ser considerada como um meio de Tradução.

A Tradução é um dos principais mecanismos sociais facilitadores do sistema social de interação com o meio ambiente, sendo um fenômeno de barreira social. Está "localizada" nas fronteiras entre as unidades de interação social, sejam quais forem; e no sistema social como um todo (não necessariamente uma nação-estado, mas qualquer unidade social - de uma conversação a um sistema global - que possa ser descrita como sistema). Assim sendo, em poucas palavras, a visão da ação tradutória está subjacente à ideia de Tradução como um fenômeno social. Essas propriedades da Tradução foram discutidas em outro trabalho (Tyulenev).

\section{O que há de errado no senso comum}

Algumas considerações devem ser tecidas sobre o senso comum, o qual pode ser definido como "[...] aquele conhecimento rico, porém desorganizado, não-sistêmico, frequentemente inarticulado e inefável que utilizamos para conduzir nosso cotidiano" (Bauman 8).

Sem dúvida, a Sociologia da Tradução nos ETs, hoje, é baseada na compreensão do senso comum para certos termos. Por exemplo, Tuija Kinnunen e Kaisa Koskinen queixam-se de que a noção de "ação é amplamente discutida, mas, a "[...] fácil adoção do termo nos Estudos da Tradução, provavelmente, indica que o assunto merece ser investigado por meio de uma análise mais detalhada" (6).

Kinnunen e Koskinen continuam com uma referência útil a Hélène Buzelin sobre a aplicação da Teoria das Redes de Latour 
e apontam que esta "[...] equaciona indivíduos, agentes e ações" que "[...] podem revelar-se algo problemático, uma vez que a ação pode ser englobada por atores não-humanos, como instituições e organizações, de modo que os agentes humanos encontrem obstáculos significantes para a execução de suas atividades". ${ }^{3}$

A visão comum do tradutor e de seu trabalho é pautada tacitamente na noção acordada sobre tradutor e texto traduzido. Se aqueles que decidimos estudar como tradutores são simultanemante escritores, críticos, advogados, filósofos, professores, sacerdotes, monges, reis, diplomata, etc., como sabemos que eles são também tradutores? Obviamente, há uma propensão à resposta: "Porque eles traduzem". "O que significa, então, traduzir?" Uma resposta mais precisa é necessária.

Neste ponto, qualquer estudioso dos ETs que aprendeu bem, a partir das proposições de Gideon Toury, a teoria de que a definição de Tradução deve ser deixada para quem a faz e/ ou a usa, compreenderia a que fins tais questionamentos conduzem. ${ }^{4}$ Contudo, alguém poderia ingenuamente continuar: Como todos (em todos os estudos de caso) sabem que o que estudam é Tradução? É porque são tradutores que o fazem? Ou será porque os pesquisadores estudam tal fenômeno? (Toury esforça-se por evitar a circularidade de uma argumentação cíclica). Ou será que só o termo Tradução assegura a verificação da atividade tradutória e não de nenhum outro fenômeno?

Sem dúvida, o senso comum acadêmico nos ETs é o único guia, quer se admita ou não. Tem-se visto a Tradução por tempo suficiente para reconhecê-la mesmo quanto disfarçada com "máscaras" pós-coloniais, mas, em vez de tentar formular o que exatamente faz a Tradução ser Tradução, ainda se recaí em ideias muito simplistas. Assim, é preciso abandonar as concepções comuns quando se estuda Tradução de um ponto sociológico que lide com os fenômenos supraindividuais e no qual a lógica regular não se aplique.

Mesmo "quando acreditamos ser livres dos julgamentos do senso comum, eles nos tomam de surpresa", e o leitor de $A s R e$ gras do Método Sociológico é advertido a não se esquecer disto, 
porque os “[...] meios de pensamento são mais propensos a serem adversos ao invés de favoráveis aos estudos científicos dos fenômenos sociais [...]" (53)

A discussão de Durkheim sobre a palavra "chave" para o seu estudo sobre "suicídio" é interessante em comparação com as proposições dos ETs no que tange ao termo Tradução. A palavra "suicídio", como é usada nas conversas diárias, parece não apresentar nenhuma definição superficial, contudo, se o cientista depende do uso comum de palavras,

[...] fica suscetível a palavras tão vagamente definidas que varia de um exemplo a outro de acordo com o que cada conversação demanda, mas isto sempre resulta em categorias de coisas bem diferentes que são trazidas à baila de maneira vaga sob os mesmos rótulos ou realidades das mesmas coisas chamadas por diferentes nomes, desde que a classificação que produzem não derive de nenhuma análise metodológica, mas expresse meramente as impressões confusas de pessoas comuns. [...] Portanto, nossa primeira tarefa deve ser decidir a ordem das coisas que nos propomos a estudar sob a nomenclatura de "suicídio". Para fazer isso, devemos considerar se, entre os diferentes tipos de morte, há alguns que têm em comum características que são objetivas o suficiente para serem conhecidas por qualquer bom observador e particulares o suficiente para não serem encontradas em qualquer lugar, mas, ao mesmo tempo, próximas o suficiente daqueles que são comumente nomeados pelo termo "suicídios", de forma a serem utilizados sem o caráter violento do uso cotidiano. (Durkheim (B) 15-16)

Reconhecidamente, na sua curta, mas dinâmica história, os ETs, inicialmente, realizaram exatamente o percurso apontado por Durkheim - tentaram definir Tradução de maneira restrita e científica, bem como Durkheim tentou definir o "suicídio". Os ETs ainda reconsideraram suas estratégias, vendo que definições muito 
restritas (centradas na equivalência linguística) não funcionaram, porque distorceram a descrição da práxis e as compreensões do traduzir em toda sua complexidade além do espaço e tempo.

Em seguida, Toury sugeriu lançar uma restrição do fenômeno, propondo a noção de "tradução assumida" ((A) 27; (B) 31). Isso abriu os ETs para o fecundo campo de investigação que tem sido conduzido por ambos paradigmas, descritivo e sociocrítico cultural, pós-colonial e sociológico. Mas, ao mesmo tempo, foi-se ainda mais longe, ao afirmar que tentar definir Tradução é uma questão discutível, colocando-a sob a égide de conceituações comumente oferecidas por qualquer um, em qualquer lugar e a qualquer momento.

Os três postulados, sugeridos por Toury, que limitaram a compreensão da Tradução e salvaram os ETs da anarquia não foram postos de lado, mas mencioná-los é considerado inaceitável. Contudo, se há pretensão de desenvolver qualquer pesquisa na área, seja com base em teorias coloniais ou pós-coloniais, sincrônicas ou diacrônicas, contemporâneas ou históricas, ainda que apenas na superfície, encontrar-se-á, com certeza, uma definição implícita similar aos postulados de Toury.

Assim, a definição de Tradução tem sido considerada tão discutível que praticamente não foi mais debatida. O resultado é que toda a investigação é sustentada por alguns fundamentos básicos que não são aprofundados e acabam sendo trabalhados apenas na superfície, acumulando definições planas emprestadas de profissionais ou usuários.

Os ETs completaram um ciclo e provavelmente é hora de retornar para onde, enriquecidos graças à relativização da visão da Tradução, tiveram seu início. Chegou a hora de desenterrar as visões implícitas e explicá-las; de utilizar a definição libertadora de Toury para além seus postulados modificadores (conduzindo-a para fora do contexto predominantemente literário).

A Tradução deve ser investigada com uma grande dose de ingenuidade ${ }^{7}$, a fim de superar o senso comum. Neste contexto, é

\footnotetext{
${ }^{7}$ Nas obras de Durkheim $(2004,2006)$, o autor sugere que a metodologia científica deve ser tão ingênua quanto uma criança que inicia suas compreensões do mundo que a circunscreve.
}

Cad. Trad., Florianópolis, v. 39, nº 2, p. 339-378, mai-ago, 2019. 
instrutivo ver como Durkheim explicou por que é necessário olhar para os fenômenos sociais como "coisas". Primeiramente, deixa claro que não quer dizer que os fatos sociais são "coisas" materiais. Afirma que os primeiros são "coisas pelo mesmo direito que as coisas materiais, embora de uma forma diferente" e continua:

O que, na verdade, é uma coisa? Uma coisa difere de uma ideia da mesma forma que o que sabemos de fora é diferente do que conhecemos a partir do interior. Uma coisa é qualquer objeto de conhecimento que nossa compreensão não penetra naturalmente; é tudo que podemos conceituar adequadamente por meio de um simples processo de análise mental; é tudo que a mente não pode ter êxito na compreensão exceto indo fora de si, na forma de observações e experimentos, que progride das características mais externas e imediatamente acessíveis para aquelas que são menos visíveis e mais profundas. Tratar os fatos de uma certa ordem de coisas, não é, portanto, classificá-los em uma categoria particular da realidade; é, ao invés disso, observar uma atitude mental particular sobre as outras. Começamos o estudo adotando o princípio de que somos totalmente ignorantes do que as coisas são, e de que as suas propriedades características, como as causas desconhecidas de que dependem, não podem ser identificadas mesmo por meio de seus mais intrínsecos elementos. (54-55)

Com esse tipo de ingenuidade, pode-se, depois de todas essas décadas de investigação enriquecedora e esclarecedora, voltar às fontes. Tal regresso deve observar os seguintes princípios (com base em Durkheim [65-66]):

(1)Devemos proteger-nos contra surtos de senso comum na forma de noções preconcebidas (por exemplo, o que são tradução, tradutor, ação).

(2)A pesquisa deve identificar e definir os fenômenos que 
são colocados no mesmo grupo, com base em certas características externas.

(3)O grupo sob investigação deve permitir incluir todos os fenômenos que se encaixam na definição.

(4)Quando as traduções são estudadas como fatos sociais, devem ser consideradas "a partir de um aspecto em que apareçam separadas de suas manifestações individuais".

Portanto, de acordo com o Princípio (4), ao seguir a visão de Sociologia de Durkheim, atenta-se para todos os estudos que não separam as manifestações individuais dos fatos sociais e de seus aspectos gerais. Isso não quer dizer que as demais investigações estão erradas, mas, geralmente, o risco é de que o pesquisador (especialmente sem a formação sociológica) concentre-se na vida-história do indivíduo e esqueça que a análise se pauta no prisma do socialmente generalizável. (É preciso dizer que não há nada de errado em escrever biografias, mas deve-se pensar duas vezes antes de afirmar que se trata de uma pesquisa em Tradução com fins sociológicos).

Como Anthony Giddens nos ajuda a compreender:

Muitos pesquisadores da obra de Durkheim têm falhado em conectar sua discussão analítica (e rejeição) do individualismo como uma abordagem metodológica para a teoria social com sua concepção desenvolvimentista da emergência do individualismo como moralidade trazida à baila pelo crescimento da diferenciação na divisão do trabalho. [...] Os escritos de Durkheim representam uma tentativa de separar o "individualismo liberal", relacionado a características da ordem social moderna, do "individualismo metodológico". A tentativa [ de Durkheim] de desvincular a moral do individualismo metodológico é mais tênue e profunda do que tem sido apontado por muitos críticos, o que resulta é uma síntese frágil e insatisfatória $(210-212)$. 
Giddens esclarece que a "Sociologia não pode ser baseada em uma teoria que trate o indivíduo como o ponto de partida da análise [...]" (211). Deve-se ser cuidadoso ao conduzir uma pesquisa sociológica para pintar um retrato de um indivíduo socializado; foco e, consequentemente, metodologia devem ser verificados e devidamente balanceados.

Outra manifestação de senso comum nos ETs é que os estudiosos não conseguem discernir entre Ativismo Social e estudo da Tradução. Lutar por consciência social na atividade tradutória e para os tradutores/ intérpretes é uma nobre missão, mas não pode ser confundida com a pesquisa acadêmica, porque tal confusão é susceptível de resultar em enviesamento e distorções conscientes ou inconscientes. A objetividade fundamenta-se em um espírito de não julgamento e não tem nada a ver com reunir forças para uma causa. Em Durkheim, "o bem e o mal não existem na ciência" (Durkheim: 67). Como Mary Douglas, ao estudar a formação das religiões com base em teorias durkheimianas, observa:

Ao final, o preconceito moral tem de ser desconsiderado e a linguagem de exortação e repreensão precisa ser amenizada. $\mathrm{O}$ apelo às emoções tem de ser eliminado. Isso é precisamente o que Durkheim tentou fazer quando nos pediu para prestar atenção aos "fatos sociais" e para a renunciar as bases explanatórias da "Psicologia". Querendo estabelecer uma teoria unificada da sociedade e do conhecimento, ele arranjou a linguagem para desvelar as cargas emocionais ocultas e colocá-las em pauta. (15)

Como qualquer Ciência, a Sociologia é postulada como "destituída, ou quase, de toda eficácia prática, e, portanto, sem justificativa real para a sua existência" (Durkheim 67). Nesse mesmo âmbito, as teorias da Tradução parecem ainda ter de se inferiorizar e justificar, buscando razões pelas quais estudos sobre a prática tradutória sejam necessários.

Cad. Trad., Florianópolis, v. 39, no 2, p. 339-378, mai-ago, 2019. 
Atualmente, o argumento do senso comum contra a Teoria da Tradução é de que ela pouco tem a ajudar os praticantes desta atividade, que tanto podem traduzir sem teoria ou precisar apenas de alguma formação prática. A teoria existe porque a ação de traduzir existe, e, sem dúvida, ajuda a prática. O mecanismo de sua relação pode ser visto como o mesmo mecanismo da relação entre Linguagem e Linguística. Podemos falar sem Linguística, mas aqueles que querem trabalhar com a Linguagem certamente têm um desempenho melhor quando estudam o idioma e a sua (s) própria (s) língua(s) de trabalho. Quem questiona a necessidade de estudo da Linguística? Tradutores que negam a necessidade de uma teoria podem ser talentosos, mas têm uma visão de curta distância, então, por que teóricos da Tradução deveriam ouvi-los? Deve o linguista ouvir um falante nativo de uma língua que dúvida das razão da existência da Linguística?

Por outro lado, um fator importante jaz sobre como justificar os ETs quando a sua existência é questionada pela ciências-irmãs, tais como a Linguística Aplicada e a Literatura Comparada. Sem entrar em detalhes, o presente trabalho sugere que, neste sentido, os ETs não têm feito o suficiente na definição de seu único objeto, projetando-se obstinadamente sobre a ideia de transferência interlingual e procurando descartar outras hipóteses, a fim de apresentar um olhar mais preciso sobre o fenômeno da transferência.

Em muitos casos, decide-se retomar o conceito de tradução propriamente dita (Jakobson 114), no entanto, é interessante explorar outros tipos de definição, a fim de encontrar uma boa teorização. Contudo, muitos estudiosos explicam sua escolha por seguir o princípio da tradução interlingual. dizendo que tal conceito não pressupõe a mudança de canal "[...] com um número crescente de diferenças a partir do original em todas as camadas, inclusive as intencionais" (Dollerup 305).

O problema com este tipo de declarações, no entanto, é que, embora qualquer pesquisador de Tradução, mesmo superficialmente familiarizado com o Funcionalismo, estranhe outras definições; ainda que esteja susceptível a refutar que o processo tradutório 
pode ser intersemiótico (mudando de canal) e que não goste de ser forçado a considerá-lo, por que não aceitar que o paradigma funcionalista engloba também a tradução intersemiótica? Ou a última não é considerada uma ação tradutória? A teoria semioticista de Jakobson foi simplesmente levada a incluir esta transferência no grupo de fenômenos que classifica como Tradução? Se assim for, por que seu artigo Sobre os Aspectos Linguísticos da Tradução é considerado um clássico e incluído nas leituras de ETs?

Talvez, fosse melhor excluir o artigo do nosso cânone como uma potencial fonte de heresias. Se ele estiver certo, no entanto, pelo Princípio (3) apontado acima, o grupo sob investigação deve incluir todos os fenômenos que se enquadram na definição de Tradução; e o trabalho é investigar o que torna a tradução intersemiótica semelhante aos outros tipos de tradução e no que isso difere e forma um subgrupo. Sem dúvida, é neste tipo de estudos que o futuro dos ETs sustenta-se, porque tais estudos prometem ampará -los com seu estilo único e incomparável.

\section{Fato Social}

O que é um fato social? Este é o conceito central de Durkheim e uma de suas mais importantes contribuições para a Sociologia. Fatos sociais são definidos como " [...] maneiras de agir ou de pensar, reconhecíveis pela característica distintiva que eles são capazes de exercer, gerando uma influência coercitiva sobre a consciência individual" (56). Fatos sociais, como quaisquer fenômenos sociais, são exteriores aos indivíduos (Durkheim, 55).

Ao descrever a influência que os fatos sociais têm sobre os indivíduos, Durkheim introduziu a noção de restrição social, que, segundo ele, implica

[...] que formas coletivas de agir ou pensar possuem uma realidade exterior aos indivíduos que, em qualquer mo- 
mento, atuam em conformidade. São coisas que têm a sua própria existência. O indivíduo encontra-as já formadas e nada pode fazer para eliminá-las ou alterá-las; é obrigado a tomar conta delas e é muito mais difícil (embora não impossível) para ele alterá-las, pois, em graus variados, eles compartilham o material e a supremacia moral que a sociedade exerce sobre os seus membros. (57)

Durkheim não nega que os indivíduos têm seu papel na criação de restrições sociais, (Seus críticos nem sempre apreciam esse aspecto de sua teoria.) mas é sempre necessário mais de um indivíduo para influenciar os fatos sociais. A síntese resultante das vontades individuais é um produto externo a cada participante tomado em separado. Assim, o caminho direciona-se do indivíduos para a instituição, que Durkheim define como "[...] todas as crenças e todos os modos de comportamento instituídos pela coletividade [...]" (57).

Portanto, a Sociologia é " [...] a ciência das instituições, de sua gênese e de seu funcionamento" (Durkheim 57). É importante ressaltar que somente determinadas ações socialmente humanas são fatos sociais. Funções biológicas, tais como respirar ou dormir não o são; mas os papéis sociais de atuar, por exemplo, como um membro de uma família ou de uma organização enquadram-se nesta definição porque são determinados socialmente e, nesse sentido, as práticas que seguimos “ [...] funcionam independentemente da utilização que fazemos delas” (Durkheim 58).

O coercitividade dos fatos sociais é manifesta na forma como resistem à alteração: “[...] fatos sociais [são considerados] como coisas cuja natureza, no entanto, flexível e maleável, é não mutável arbitrariamente" (Durkheim 53). Uma pessoa é presa se infringe a lei; ela é preterida se não age de acordo com um costume ou não atende às expectativas. Fatos sociais são sociais exatamente porque se originam não em uma pessoa. "[P]odem ter nenhum outro substrato que não a sociedade, seja a sociedade como um todo, ou um dos grupos que a compõem, tais como denominações religiosas, políticas, literárias e associações profissionais, etc.” (Durkheim 59). 
A teorização de Tradução em nível social deve sempre ser realizada com isto em mente: fatos sociais, a Tradução entre eles, são "o próprio campo da Sociologia" (Durkheim 59).

Neste ponto, Durkheim aborda seus críticos que acham que sua teoria está fazendo dos membros individuais da sociedade marionetes:

É verdade que, quando definimos [fatos sociais] pela palavra 'restrição', corremos o risco de enfurecer os que zelosamente suportam o individualismo absoluto. Já que mantêm a proposta de que o indivíduo é completamente autônomo, parece-lhes que é o indivíduo é diminuído cada vez que lhe fazem pensar que não é completamente auto-determinado. Mas como é indiscutível que a maioria de nossas ideias e inclinações não são desenvolvidas por nós mesmos, e sim vem de fora, elas só podem tornar-se parte de nós ao nos serem impostas. [...Contudo] qualquer restrição social não exclui necessariamente a personalidade individual. (59)

Entre as restrições, são bem definidos os sistemas sociais, tais como o Direito, os dogmas religiosos, as instituições financeiras, mas também existem aquelas menos claras como as tendências sociais. As últimas são óbvias em uma multidão ou grupo de protesto ou apoio, ali, nenhum indivíduo pode ser identificado como a origem do entusiasmo ou da indignação de um grupo. Estas emoções são compartilhadas e intensificadas por todo o grupo; ocorrem a cada participante, a partir de fora. Enquanto há acordo com esta corrente, pode-se pensar que não há nenhuma pressão exercida sobre os indivíduos, mas esta pressão será prontamente manifesta assim que decidirem resistir ao fluxo geral. "Somos, portanto, vítimas de uma ilusão que nos faz acreditar que nós mesmos produzimos o que nos foi imposto de fora [...]" (Durkheim 60).

Os ETs têm menos dificuldade em reconhecer esta dependência da soma de textos traduzidos ou de tradutores (escolas, tendências) em instituições sociais (agências, editoras, normas dominantes e 
padrões, etc.). É, talvez, mais difícil, neste campo, admitir tal influência, ou melhor, seu peso no nível individual.

Parece, de alguma forma, que a pressão não é tão intensa. Mas uma analogia é possível, ou seja, assim como a pressão do ar não é mais fraca ou mais forte em cada ser humano do que na multidão, assim a pressão social também não o é. Ainda há uma gama de possibilidades (de agir de acordo com uma norma imposta para resistir ao ato), mas o que é importante e, muitas vezes esquecido, é que o tradutor é sempre socialmente contextualizado, ou, mais precisamente, socializado e sua gama de possibilidades de ação é determinada pela sociedade, mesmo que tenha opções de resistência. Graus de liberdade são também socialmente determinados. Isto se torna óbvio se, por exemplo, for comparado como e por que um tradutor seria punido por sua resistência em uma sociedade europeia contemporânea e/ou em outra medieval.

Mas a questão não é tanto sobre a liberdade ou a falta dela. A chave é a interdependência social. Esta interdependência e suas manifestações devem ser objeto de pesquisas sociologicamente direcionadas sobre Tradução. É um desafio ir além do senso comum da visibilidade individual.

\begin{abstract}
À primeira vista, [fatos sociais, tais como inclinações para o suicídio em uma determinada sociedade] parecem inseparáveis das formas que assumem em casos particulares. Mas as estatísticas nos fornecem os meios de isolá-los. [Os fenômenos individuais não são excluído de análise, mas devem ser complementados com abordagens estatísticas]; assim, uma vez que cada uma destas figuras inclui todos os casos individuais, sem discriminação, as circunstâncias individuais que podem desempenhar algum papel na produção do fenômeno se anulam mutuamente e, consequentemente, não entram em sua determinação. $O$ que a média expressa, portanto, é um estado específico da mente coletiva. (Durkheim 60-61)
\end{abstract}


Para ter certeza, métodos estatísticos auxiliam a superar o ponto de vista comum sobre os fatos sociais, mas não são o único tipo de métodos. A Sociologia Moderna emprega tanto metodologias quantitativas quanto qualitativas, e estudiosos da Tradução podem aprender mais sobre elas a partir dos sociólogos.

Coisas sociais são personificações das ideias que as pessoas têm sobre a sociedade e suas instituições. Tais ideias são o objeto de estudo do sociólogo (Durkheim 63).

Ainda assim, o sociólogo ou o sociólogo na Tradução deve ser cuidadoso sobre como e onde essas ideias podem ser encontradas. É importante não esquecer de que as coisas são coisas e isso significa que elas devem ser tratadas como entidades externas e é apenas como tal, como dados externos, que podem ser usados na investigação.

Em adição ao que já foi dito acima, a sociedade e os fatos sociais são também teorizados como coisas no sentido de sua visibilidade social. Os pensamentos são socialmente invisíveis até que se demonstrem como gestos, palavras e frases, comportamentos, etc., ou seja, algo que é transmissível a outros membros da sociedade. Tais coisas transmitidas constituem o tecido social, que é o assunto da Sociologia, incluindo a Sociologia da Tradução.

Assertivas com o tradutor deve ter sentido/pensamento, ou $o$ tradutor sonhou..., não são mais que conjecturas do pesquisador e não se adequam aos princípios da Sociologia, pois nenhum pesquisador tem um raio-X mágico que pode penetrar diretamente o social em si mesmo. Pode-se avaliar coisas, uma pedra ou um animal ou outro ser humano ou um fato social, apenas com base no que é projetado pela coisa de dentro para fora, tornando-a detectável e observável. Como ter certeza de que o tradutor sonhou com alguma coisa? Fatos socio-tradutórios devem ser separados de adivinhações e do que os tradutores pensam enquanto produzem seus textos traduzidos. E o que esses sonhos, mesmo que fossem verdade, têm a ver com Sociologia? Mais uma vez, nas palavras de Durkheim: 
[...] os fenômenos sociais são coisas e devem ser tratados como coisas. [S]ão os únicos dados disponíveis para o sociólogo. Uma coisa é, em efeito, tudo o que é dado, oferecido, ou melhor, forçado, a nossa observação. Tratar fenômenos como coisas é tratá-los como dados que fornecem o ponto de partida para a ciência. [...Aliás,] devemos considerar os fenômenos sociais em si mesmos, separados dos seres conscientes que os representam; devemos estudá-los de fora, como coisas externas, pois é precisamente assim que eles aparecem para nós. [...] Mesmo os fenômenos que mais parecem consistir em arranjos arbitrários devem ainda ser considerados a partir desta perspectiva. (63-64)

Mas, mesmo se os tradutores individuais fossem estudados devidamente, dever-se-ia ter muito cuidado (e não é fácil para os estudiosos da Tradução, que, em grande parte, não possuem a formação sociológica adequada) em manter uma distância entre si mesmo e o objeto de estudo, que é, entender o tradutor/tradução como uma coisa-em-si, sobre a qual se julga apenas com base na evidência social visível, por um lado, e no objeto de estudo individual (tradutor ou texto traduzido) no contexto social, por outro lado.

O objeto de estudo individual não deve ser visto como alguém/ algo que pode ser adicionado a um outro alguém ou algo criando a sociedade. É por isso que, no estudo das propriedades sociais de Tradução, o pesquisador, ao olhar para o indivíduo, deve manter seu/seus olhos sobre o coletivo. A Tradução como um fato social não pode existir se não houver atos individuais de traduzir, e, é nestes exatos atos que se verifica o dilema "sociedade vs. indivíduos": "a sociedade não é a mera soma de indivíduos, mas o sistema formado por sua associação, o qual representa uma realidade específica que tem suas próprias características" (Durkheim (C) 129). Portanto, os habitus de tradutores individuais são uma condição necessária, mas não suficiente condição para teorizar a Tradução como um fenômeno social: 
O grupo pensa, sente e age de forma totalmente diferente da forma como seus membros fariam se estivessem isolados. Se, portanto, começarmos a estudar esses membros separadamente, vamos entender nada sobre o que está ocorrendo no grupo. (Durkheim (C) 129)

\section{Considerações Finais}

Há mais linhas de pesquisa promissoras que o pensamento clássico de Durkheim impulsiona que aquelas aqui mencionadas. Por exemplo, seria instrutivo aprofundar os princípios da distinção entre normalidade e morbidade, patologias e fatos sociais (68-70). Isso poderia levar os pesquisadores de Tradução a encontrar ideias sobre como estudar este fenômeno do ponto de vista topológico e comparativo, a fim de resolver um conflito de opiniões entre o que Durkheim chama de disputa entre "historiador vs. filósofo" ou entre o nominalismo de historiadores (que vêm as sociedades como constituídas de uma infinidade de indivíduo e tipos incomparáveis) e o extremo realismo dos filósofos (para quem "todos os agrupamentos [...] são apenas contingentes e agregamentos provisórios, sem qualquer realidade individual," "só a humanidade é real, e, é a partir de atributos gerais da natureza humana que toda a evolução social deriva”):

Consequentemente, para os historiadores, a história é apenas uma sequência de eventos que estão ligados, mas não se repetem; para os filósofos, estes mesmos acontecimentos têm valor e interesse apenas como uma ilustração das leis gerais que estão inscritas na constituição do homem e que possuem influência sobre o curso do desenvolvimento histórico. (Durkheim (C) 108)

Sendo assim, estas ideias ajudariam a lançar mais luz sobre as discussões acerca do grau de generalizações vs. particularizações nos ETs. 
Outra questão importante é a preeminência do coletivo na perspectiva sociológica comparada com o geral. É importante ressaltar a hierarquia entre os dois, porque o senso comum os tem na ordem inversa e, assim, falta a compreensão dos fatos sociológicos como independentes de suas manifestações individuais e concepções qualitativas simplistas de coletividade:

Pode ser considerado que um fenômeno só pode ser coletivo se for comum a todos os membros da sociedade, ou, ao menos, para a maioria, e, portanto, se for geral. Este é, certamente, mas, se ele é geral é porque é coletivo (isto é, mais ou menos obrigatório), em vez de ser coletivo, porque é geral. É uma condição de grupo que se repete nos indivíduos porque se impõe a eles. É encontrada em cada parte porque está no todo, ao invés de estar no todo porque ele está nas partes. (Durkheim 61-62)

Tais e semelhantes ideias sociológicas contraintuitivas podem se tornar uma fonte de inspiração e, definitivamente, de revelação para pesquisadores em Tradução.

Anteriormente apontou-se o problema de confundir fato social com ativismo social. Um outro exemplo pode ser verificado neste sentido, prejudicando metodologicamente a teorização, como quando cultural e social não são adequadamente diferenciados.

Algumas pesquisas sugerem que a Tradução pode ser compreendida como uma prática cultural associada com "poder, ideologia e fatores semelhantes" (Wolf 342). Mas tanto poder quanto ideologia são considerados questões sociais de bona fide ativamente discutidas pelos principais sociólogos, como Max Weber, Talcott Parsons, Nikolas Lehmann, Reinhardt Bendix, Julien Freund, Peter M. Belau e muitos outros (Walkman, Tutsis and Ziti; Elias; Lehmann; Bauman). Qual é, então, a diferença entre cultural e social? Andrew Chesterman afirma que a pesquisa que é categorizada como pautada em estudos culturais, está, na verdade, mais perto de Sociologia. Sendo assim, o autor salienta a necessidade de deli- 
near uma limite entre temas sociológicos e culturais. Ao adicionar questões de ordem psicológica a estas duas categorias, Chesterman sugere uma estrutura tripartite da pesquisa em Tradução (Duarte, Assis Rosa and Seruya 11):
1) cultural (valores, tradições, ideias e ideologias);
2) sociológica (observação de comportamentos grupais de tradutores e das instituições em que trabalham);
3) cognitivo (processos mentais relacionados com a tradução, tomada de decisão).

Ainda não está muito claro em que circunstâncias as categorias 1) e 2) devem ser separadas, uma vez que, de acordo com a lógica durkheimiana, ambas são fatos sociais e, portanto, bases legítimas de pesquisa sociológica e, consequentemente, requerem semelhantes abordagens metodológicas. Para resolver este problema, devese examinar a forma como a Sociologia e os Estudos Culturais explicam a sua relação. Como alternativa, talvez, seja importante que os pesquisadores se contentem com a separação da pesquisa em Tradução em seus fatores psicológicos e sociais, como Durkheim sugere, e perguntarem-se: Quais são as manifestações de Tradução como atividade social vs. psicológica?

Finalmente, deve ser dito que é aconselhável que os estudiosos de ETs, em suas tentativas de teorizar a Tradução como atividade social, familiarizem-se com a teoria sociológica. Não se dever descartar as teorias sociológicas clássicas pensando que as questões que dizem respeito à Tradução foram alteradas atualmente para que os teóricos clássicos, como Durkheim, não possam mais nos amparar.

Os ETs, em suas tentativas sociológicas, quando voltados para teorias como as de Bourdieu, Luhmann, etc., fazem-no sob as perspectivas dos pais da Sociologia, em cujas teorias modernas constroem suas bases, ainda que deixando passar alguns pontos importantes sobre a teorização do social ou correndo o risco de reinventar a roda, exatamente como Ian Craib nos adverte (2). 


\section{Agradecimentos}

Eu gostaria de expressar a minha gratidão a Smaïl Khris por sua ajuda na preparação do manuscrito.

\section{Referências}

Bandia, P. F.; Bastin, G.L. "Rencontres Est-Ouest/Leste-Oeste Encontra". TTR. XXIII. 1, (2010).

Bauman, Z. Thinking Sociologically. Oxford: Basil BlackwelL, 1990.

Callon, M." Some Elements of a Sociology of Translation: Domestication of the Scallops and the Fishermen of St Brieuc Bay." In: Law, J. (Ed.) Power, Action and Belief: A New Sociology of Knowledge? London, Boston, and Henley: Routledge \& Kegan Paul (1986): 196-233.

Cheung, M. P.Y. "Reconceptualizing Translation: Some Chinese Endeavours." Meta. 56.1, (2011): 1-19.

Craib, I. Classical Social Theory: An Introduction to the Thought of Marx, Weber, Durkheim, and Simmel. Oxford and New York: Oxford University Press, 1997.

Dollerup, C. Tales and Translation. Amsterdam/Philadelphia: John Benjamins, 1999.

Douglas, M. Natural Symbols: Explorations in cosmology. London and New York: Routledge, 2008.

Duarte, J.f.; Assis Rosa, A.; Seruya, T. (Ed.). Translation Studies at the Interface of Disciplines. Amsterdam and Philadelphia: John Benjamins, 2006. 
Durkheim, E. (A). On Suicide. Translated by Robin Buss. London: Penguin Books, 2006 [1897].

Durkheim, E. (B). Readings from Emile Durkheim. Edited by Kenneth Thompson. London and New York: Routledge, 2004.

Durkheim, E. (C). The Rules of Sociological Method and Selected Texts on Sociology and Its Method. Edited with an introduction by Steven Lukes. Translated by W. D. Halls. Houndmills, Basingstoke, Hampshire, and London: The Macmillan Press Ltd, 1982/1895.

Elias, N. What Is Sociology? Tradução de Stephen Mennell and Grace Morrissey. New York: Columbia University Press, 1978/1970.

Fish, J. Defending the Durkheimian Tradition: Religion, Emotion and Morality. Aldershot, Hants, Burlington, VT: Ashgate, 2005.

Gambier, Y.; Doorslaer, L van. (Ed.). Handbook of Translation Studies. 1. Amsterdam/Philadelphia: John Benjamins, 2010.

Giddens, A. The 'Individual' in the Writings of Emile Durkheim. European Journal of Sociology. 12.2 (1971): 210-28.

Halverson, S. “Translation”. In: Gambier, Y.; Doorslaer, L van. (Ed.). Handbook of Translation Studies.1. Amsterdam/Philadelphia: John Benjamins (2010): 378-384.

Jakobson, R. “On Linguistic Aspects of Translation”. In; Venuti, L. (Ed.) The Translation Studies Reader.London and New York: Routledge (2000/1959), p. 113-118.

Jones, S. S. Durkheim Reconsidered. In: Kinnunen, T.; Koskinen, K. (Ed.) Translators' agency. Tampere: Tampere University Press, 2010.

Luhmann, N. Die Gesellschaft der Gesellschaft. Frankfurt am Main: Suhrkamp, 1998. 
Luhmann, N. Macht. Stuttgart: Enke, 1975.

Lukes, S. "Prolegomena to the Interpretation of Durkheim". European Journal of Sociology. 12. 2 (1971): 183-209.

Mcelduff, S.; Sciarrino, E. (Ed.) Complicating the History of Western Translation. The Ancient Mediterranean in Perspective. Manchester and Kinderhook, NY: St Jerome, 2011.

Ricci, R.; Van Der Putten, J. (Ed.) Translation in Asia: Theories, Practices, Histories. Mnchester and Kinderhook, NY: St Jerome, 2011.

Robinson, D. The Translator's Turn. Baltimore and London: The Johan Hopkins University Press, 1991.

Snell-Hornby, M. (A) The Turns of Translation Studies. Amsterdam/Philadelphia: John Benjamins, 2006.

Snell-Hornby, M. (B). The Turns of Translation Studies. In: Gambier, Y.; Doorslaer, L van. (Ed.). Handbook of Translation Studies. 1. Amsterdam/ Philadelphia: John Benjamins (2010): 366-370.

Swansea. The Author - Translator in the European Literary Tradition. Programme and Abstracts. Swansea, UK: Swansea University Press, 2010.

Thompson, K. Preface to the Revised Edition. In: KUMIKO, T. Voices of the Invisible Presence. Amsterdam/Philadelphia: John Benjamins, 2004.

Toury, G. (A). “A Rationale for Descriptive Translation Studies”. Dispositio. 7 (1982): 22-39.

Toury, G. (B) > Descriptive Translation Studies and beyond. Amsterdam/ Philadelphia: John Benjamins, 1995.

Tyulenev, S. Applying Luhmann to Translation Studies: Translation in Society. New York and London: Routledge, 2011. 
Wallimann, I; Tatsis, N. C.; Zito, G. V. On Max Weber's Definition of Power. Journal of Sociology. 13.3 (1977): 231-235.

Way, C. "Translation as Social Action". Conference presentation. http://isg. urv.es/filag/videos/080526_Way_p1.wmv. 2008. Acesso em: 21 dec. 2011. December 2011.

Wolf, M. Sociology of Translation. In: Gambier, Y.; Doorslaer, L van. (Ed.). Handbook of Translation Studies.1. Amsterdam/Philadelphia: John Benjamins, (2010): 337-343.

Zlateve, P. (Ed). Translation as Social Action: Russian and Bulgarian Perspectives. London and New York: Routledge, 1993.

Recebido em: 05/11/2018

Aceito em: 27/03/2019

Publicado em maio de 2019

Talita Serpa. E-mail: talitasrp82@gmail.com. ORCID: https://orcid.org/00000003-3324-9593 